\title{
A.D. Cousins y Peter Howarth (Editores): The Cambrid- ge Companion to the Sonnet. Cambridge: Cambridge Uni- versity Press, 2011.
}

A pesar de la inventiva del soneto inglés decimonónico (Wordsworth, Tennyson, Rosetti, Browning), la crítica del siglo antepasado aún sostenía, como lo relata Peter Howarth, que un verdadero soneto (inglés, se entiende) debía construirse con decasílabos, que en él deberían notarse claramente la octava y la sextina, que la estructura de la rima del poema admitía solo ciertas variaciones, que este solo podía expresar un único pensamiento que coincidiera a su vez con los cuartetos y los tercetos. Un crítico de la época-Crosland-sentenció que existían 21 «fijos, estables e inamovibles» mandamientos al componer un soneto: no se rima en «-ly», deben evitarse los prosaísmos y los americanismos, no debe exagerarse la cantidad de versos que empiezan con conjunción copulativa. En The Sonnet (1874) de Tomlinson y en la introducción a la edición de los sonetos de John Milton de Pattinson, los dos autores se preguntan si los sonetos de Wordsworth y los de Shakespeare son sonetos de verdad (p. 226).

A lo largo de sus cerca de 300 páginas, The Cambridge Companion to the Sonnet evita -quizás para no parecer obra de los referidos críticos decimonónicos- cualquier definición, cualquier caracterización o cualquier clasificación del soneto o del «ideal platónico» del soneto, aunque probablemente las suponga. En compensación, ofrece -sobre todo en los capítulos finales- un panorama amplio de las variedades de esta forma proteica que ya lleva 780 años de creada. Sin embargo, más que un elenco de formas (algunas muy nuevas y poco reconocibles: un soneto de Terrance Hayes consiste en un solo verso -«Cortamos 
el melón en sonrisas»- repetido catorce veces), el libro ofrece perspectivas interesantes acerca del valor cultural del soneto, tanto en diferentes épocas como en general.

La disposición del texto mezcla criterios genéricos e históricos: a la introducción por los editores, sigue un «triálogo» sobre el soneto a cargo de tres poetas contemporáneos («Contemporary poets and the sonnet: a trialogue» de Paul Muldoon, Meg Tyler y Jeff Hilson), una reflexión acerca de la relación entre el soneto y la lírica («The sonnet and the lyric mode» de Heather Dubrow), otra sobre subjetividad y género («The sonnet, subjectivity and gender» de Diana E. Henderson), un estudio sobre el soneto y su transmisión manuscrita, impresa y audiovisual («The English sonnet in manuscript, print and mass media» de Arthur F. Marotti y Marcelle Freiman). A continuación, sigue la secuencia histórica: los orígenes («European beginnings and transmissions: Dante, Petrarch and the sonnet sequence» de William J. Kennedy), la sensibilidad expresada por el temprano soneto amoroso en Inglaterra («Desire, discontent, parody: the love sonnet in early modern England» de Catherine Bates), los sonetos de Shakespeare («Shakespeare’s Sonnets» por A. D. Cousins), el soneto inglés de contenido religioso ( $«$ Sacred desire, forms of belief: the religious sonnet in early modern Britain» de Helen Wilcox), los sonetos postmiltonianos («Survival and change: the sonnet from Milton to the Romantics» de R. S. White), el soneto en el Romanticismo («The Romantic sonnet» de Michael O’Neill), el soneto victoriano («The Victorian sonnet» de Matthew Campbell), el moderno («The modern sonnet» por Peter Howarth) y el contemporáneo («The contemporary sonnet» por Stephen Burt).

Para un texto cuyo tema es el soneto (a secas), un contenido como el presentado arriba podría parecer anglocéntrico. Por ejemplo, se extraña un desarrollo mayor del tema de los orígenes y la formación del soneto. El libro le dedica apenas dos páginas. Y mucho más podría decirse en él del ambiente cultural y las preocupaciones matemáticas de la corte siciliana de Federico II, en la que estaban activos personajes como Giacomo da Lentini y Pier delle Vigne (cfr. el estudio de W. Pötters. Nascita del sonetto. Metrica e matematica al tempo di Federico II. Ravenna: Longo, 1998). Las páginas dedicadas a dos de los 
textos fundadores de la secuencia de sonetos (la Vita nuova de Dante y el Canzoniere de Petrarca) sí explican cómo esta evoluciona a partir de su probable iniciador, Guittone d'Arezzo, a estos dos monumentos. Resulta interesante acotar al respecto que las denominaciones del libro de Petrarca -Rime sparse o Rerum vulgarium fragmenta y Canzoniere- expresan las dos posibilidades como se han presentado los libros de sonetos: como reunión de sonetos sueltos o como un todo articulado (p. 94). La información acerca del soneto continental renacentista y barroco resulta, en mi opinión, magra y desbalanceada respecto de su verdadera importancia. Del mundo luso e hispánico, solo son nombrados, sin mayor desarrollo, Camoens, Lope y Cervantes (p.47), Boscán, Garcilaso y Sor Juana Inés de la Cruz (p.100). Si bien la omisión de Góngora o de Quevedo puede llamar la atención, probablemente sorprenda más que grandes poetas del siglo xx creadores de sonetos como Jorge Guillén (a quien Hugo Friedrich en su Estructura de la lírica moderna. Barcelona: Seix Barral, 1974, p. 54 pone como ejemplo de «la supremacía de la voluntad de forma sobre la voluntad de mera expresión», característica de la lírica moderna) o Fernando Pessoa no aparezcan siquiera mencionados. Causa perplejidad el caso de Pessoa, pues este escribe sus 35 Sonnets en inglés y sigue estrictamente el modelo del soneto inglés.

Aun con estas limitaciones, The Cambridge Companion to the Sonnet cumple con ofrecer información interesante sobre el valor histórico-cultural del soneto y, sobre todo, acerca de las perspectivas para estudiarlo. Reseñaré solo algunos artículos para mostrar estas perspectivas. Empezaré por «The english sonnet in manuscript, print and mass media» (pp. 66-83). En este artículo, Marotti y Feinman sostienen que, como observan repetidamente los teóricos de la comunicación, cada medio define «metacomunicativamente» tanto la naturaleza de los mensajes transmitidos como la relación entre emisores y destinatarios (p. 66). En sus inicios, el soneto de la temprana edad moderna, como sostiene Colin Burrow, fue «una forma ubicada en la intersección entre el documento privado y el texto impreso» (p.66). Los primeros libros de sonetos fueron secuencias de sonetos como The Arcadia (1590) y Astrophil and Stella (1591) 
de Sir Philip Sidney. Este último desató la furia sonetística que caracterizó el final del reinado de Isabel I (p. 69). Curiosamente, los sonetos de Shakespeare no generaron mucho entusiasmo (p.72). Hubo contemporáneamente otro valor para el soneto: el religioso, basado en la mezcla de lo amoroso y lo devoto que ya se aprecia desde la Vita nuova de Dante y el último tercio del libro de Petrarca, escrito luego de la muerte de Laura (p.73). La nueva cultura de la sensibilidad que aportó el Romanticismo supuso una vuelta del soneto, que apareció en nuevos contextos: novelas, revistas, panfletos. Su brevedad lo convirtió en una forma ideal para llenar los espacios libres de los diarios (pp. 7475). «El soneto», un ensayo de William Davis que apareció en la Quarterly Review llamó la atención de los lectores de la época hacia la capacidad de la forma de capturar momentos, incidentes, pensamientos y sentimientos con exactitud y brevedad, cualidades que vincularon al soneto impreso en diarios y revistas con la fotografía. El librito Sonnets of the War, por Alexander Smith y Sydney Dobell, publicado en 1855, documenta la guerra de Crimea. Sus sonetos, equivalentes a una instantánea fotográfica, influyeron en la tropa probablemente más que la célebre «The Charge of the Light Brigade» de Lord Tennyson (p.78). Durante los siglos xx y xxI, según los autores, el soneto ha declinado, aunque sobrevive en las revistas de poesía. Sobrevive, quizás en formas inéditas, en los medios audiovisuales. $\mathrm{Al}$ aparecer en filmes y en la televisión, modifican la forma como los distintos públicos los comprenden. La influencia de la poesía en la estética cinematográfica se aprecia, por ejemplo, en el interés de Sergei Eisenstein por aprovechar los efectos imaginativos y quinéticos del Paraíso perdido de Milton en el desarrollo de su lenguaje cinematográfico, especialmente en el uso del montaje (p.79). La importancia del soneto es, en este caso particular, relevante y curiosa. Sidney Gottlieb ha sugerido que un soneto de Milton («On the Late Massacre in Piedmont», de 1655) podría muy bien haber influido en la famosa escena de la masacre de las escaleras de Odessa de El acorazado Potemkin (p. 79).

La especial vinculación entre soneto, deseo, ausencia y escritura es el tema del artículo de Catherine Bates («Desire, discontent, parody: the love sonnet in early modern England», 
pp. 105-124). Bates parte de la idea de la negatividad que -dice ella- surge en el corazón de toda secuencia de sonetos: un hiato, un hueco, se abre en medio de la dicción lírica (pp. 105106). Si la carencia o el deseo pueden pensarse como verbos transitivos, entonces es el tú («ella») el que ocupa la posición del objeto directo. Sin embargo, por más que el yo llene el vacío con detalles de la belleza, la fama o la virtud de la amada, no es al tú a quien la secuencia de sonetos se refiere: el foco de interés no es el objeto deseado, sino el sujeto deseante ( p. 107). En tanto quede a una discreta distancia -como destinatario al que se importuna, como a un tú al que se apostrofa-, el tú crea una situación en la que surge un yo que importuna y apostrofa. Y mientras el tú continúe negando a su amante aquello que dice que quiere, la identidad del yo queda afirmada como sujeto, precisamente como sujeto que desea (p. 107).

Convendría más, entonces, pensar el deseo que recorre las secuencias de sonetos de la temprana época moderna -sostiene Bates- como verbo intransitivo, como si se dijera «el hablante desea», más que «el hablante desea $x$ o $y$ ». Varios aspectos de la tradición del soneto pueden explicarse si se acepta esta perspectiva, afirma. Por ejemplo, la frecuencia del oxímoron. El oxímoron surge porque la posición del sujeto es necesariamente paradójica, pues paradójicamente busca y no busca la satisfacción de su deseo. La lengua petrarquesca de la paradoja sintetiza la situación básica del sujeto de la manera más económica (p. 108). De los 366 sonetos y otras obras poéticas que componen las Rime sparse de Petrarca, no debería sorprender que los dos sonetos más difundidos hayan sido "S'amor non è» y «Pace non trovo», traducidos profusamente por expresar la naturaleza paradójica del deseo. Bates sigue explicando con estas categorías varias características del Petrarquismo, como la pluralidad de los interlocutores: Amor, Cupido, Deseo, etc. Finalmente, y a propósito de la transformación de la amada Laura en lauro, el laurel de la fama, aprecia que el deseo por la amada, por la dama, se convierte en el deseo de escribir, es decir, una relación improductiva súbitamente se transforma en una productiva: un terreno permanentemente fértil para la generación de poesía (p. 114). 
Según Peter Howarth («The modern sonnet», pp. 225244), aparentemente la Modernidad no fue benévola con el soneto, cuya severa estructura formal les evocaba a la cadena de montaje: Ezra Pound sostiene que el soneto "es el diablo" (p.225), Williams, que es «fascista» y Wallace Stevens deseaba que murieran todos (los sonetos) (p. 225). A pesar de ello, se hicieron sonetos: Robert Frost, W. H. Auden y Robert Lowell lo prueban (y muchos poetas más, si se considera en escala mundial la muestra estudiada). Finalmente, del artículo de Stephen Burt («The contemporary sonnet», pp. 245-266), cito rápidamente formas y contenidos de los sonetos (son muy variados) de poetas que han escrito en inglés en los últimos 50 años: sonetos «extravagantemente tradicionales» sobre la belleza y sobre la crueldad; sonetos de 16 versos compuestos bajo el modelo del libro Modern Love de George Meredith; sonetos en versos blancos; sonetos de amor erótico, de amor parental, de amor filial; un soneto político que es un pastiche miltoniano; un soneto compuesto enteramente por clichés; la historia de Glasgow escrita en sonetos; sonetos en los que Bruce Wayne encarna a Batman; «sonetos» sin palabras presentados como arte conceptual; sonetos sobre temas japoneses-americanos con un haiku como dístico final; sonetos en que se cuenta la historia como cuento; una muy celebrada novela literaria en sonetos que siguen el modelo de Eugenio Oneguin de Alexander Pushkin; sonetos en dialecto de Newfoundland; una corona de 15 sonetos sobre $e$-Bay. Los editores y los lectores han seguido gozando de los sonetos: el sitio web www.sonnets.org ya ha cumplido 12 años y pueden encontrarse 14 revistas que solo publican sonetos. Los poetas Edward Hirsh y Eavan Boland han editado el libro The Making of a Sonnet: A Norton Anthology. Burt precisa que hace 100 años muchos de los poemas antologados no habrían sido considerados sonetos; algunos no habrían sido considerados siquiera poemas (p. 245).

JoRge Wiesse-RebagLiaTI Universidad del Pacífico (Lima, Perú) 